\title{
CONJUNTIVITE HEMORRÁGICA AGUDA CAUSADA PELA VARIANTE DO COXSACKIEVIRUS A24, EM BELÉM, PARÁ, BRASIL, 1987.
}

Elisabeth de $O$. SANTOS, Olinda MACEDo, Maria de Lourdes C. GOMES \& Célia Maria NAKAUTH.

\section{RESUMO}

Durante um surto de conjuntivite hemorrágica aguda (CHA), ocorrido em Belém, Pará, Brasil, em 1987, foi feita investigação etiológica clínica e laboratorial, atendidos 83 pacientes e colhidos espécimes da conjuntiva, orofaringe e soro.

Na linhagem celular HEP-2 obteve-se 73 isolamentos de um enterovírus poste riormente identificado pelo Centers for Disease Control (CDC), Atlanta, Georgia, USA, como sendo uma variante do coxsackievirus A24.

Em 56 pares de soro foram realizados testes de neutralização para o EV70 e para a cepa isolada, tendo havido $57 \%(32)$ de conversão sorológica para essa última.

UNITERMOS: Conjuntivite hemorrágica; Epidemiologia; Coxsackievirus.

\section{INTRODUÇĀO}

A entidade clinica conhecida a partir de 1969 como conjuntivite hemorrágica aguda (CHA), causada sobretudo pelos enterovirus, notadamente o enterovírus 70 (EV70) e uma variante do coxsackievirus A24 (VCOXA24), desempenha hoje papel importante entre as doenças oculares de caráter epidêmico, deixando em segundo plano àquelas devidas aos adenovírus e demais agentes de natureza viral. Ocorrências de CHA de menor alcance, já foram associadas aos adenovirus 4,11 e $19^{8.13 .14}$.

A partir de 1981, quando o primeiro surto de CHA ocorreu no Norte do Brasil, em Macapá, Território Federal do Amapá e em Belém ${ }^{3 .}{ }^{10}$, dois outros surtos já foram registrados nessa úl. tima cidade, um, em $1984^{12}$ e outro, no início de 1987.
A primeira ocorrência marcou a entrada do EV70 no Rrasil e na América do Sul ${ }^{7}$. 10. 11. 12, e certamente foi importado da Ásia.

O surto de 1984, causado pelo mesmo agente, comporta a hipotese de que o vírus tenha permanecido endèmico na região pois nosso laboratório comprovou sorologicamente 3 casos desta virose no início de $1983^{12}$, em residentes de Belém que nāo se ausentavam da cidade há longo tempo.

Noticia de outros surtos sucederam-se no Brasil no sentido Norte Sul, entre os anos de 1981 e $1984^{7.11 .12}$, alguns dos quais comprovados laboratorialmente pelo Instituto Evandro Cha gas (IEC), da Fundaçāo SESP. 
SANTOS, E. de O.: MACÉDO, O.: GOMES, M. de L. C. \& NAKAUTH, C. M. - Conjuntivite hemorrágica aguda causada pela variante do coxsackievirus A24, em Belém. Pará, Brasil, 1987. Rev. Inst. Med. trop. S. Paulo, 31(3): 183-187, 1989 .

No inicio de 1987, após 6 anos da primeira notificação, foi registrada a 3 a ocorrência de CHA em Belém, agora devida a outro agente.

O presente trabalho oferece informações sobre esse surto.

\section{MATERIAIS E MÉTODOS}

Meio ambiente e população:

A cidade de Belém, capital do Estado do $\mathrm{Pa}$ rá, possui, segundo o censo de 1980, 1.211 .663 habitantes ${ }^{1}$, está situada na região Amazônica, Norte do Brasil, possui clima tropical úmido no qual ocorrem apenas duas estações que são o verào e o inverno, caracterizadas pelo menor ou maior indice de pluviosidade. A média das temperaturas máximas e mínimas fica respectivamente em torno de 31,5 a $22,5^{\circ} \mathrm{C}^{4}$.

O surto de CHA teve inicio no mês de janeiro e pode ser observado na cidade até mais ou menos meados de março.

A pesquisa foi realizada em 83 pacientes de ambos os sexos com sintomas e sinais de conjun tivite aguda, que procuraram o IEC, enviados por oftalmologistas e sobretudo por médicos do Parque Militar da Aeronáutica. Todos os casos estudados ocorreram no mês de janeiro.

Foram sistematicamente colhidos de todos os pacientes na fase aguda da doença, "swabs" da conjuntiva e da orofaringe, e soro, totalizando 166 espécimes para tentativa de isolamento de vírus, e 83 para sorologia. De 56 casos foi possivel obter a segunda amostra de sangue colhida na fase convalescente, com intervalo que variou de 15 a 45 dias após o início dos sintomas

\section{Tentativa de isolamento do vírus:}

Os "swabs" colhidos da conjuntiva e da orofaringe na fase aguda da doença, em Hank's BSS com $10 \%$ de solução de gelatina a $5 \%, 100$ unida des $/ \mathrm{ml}$ de penicilina, $0,1 \mathrm{mg} / \mathrm{ml}$ de estreptomi cina e $0.06 \mu \mathrm{g} / \mathrm{ml}$ de fungison, após centrifugaçāo clareadora foram inoculados nas linhagens celu lares VERO HEP 2, e em camundongos (CM) al binos recém-nascidos.
Detecção de anticorpos neutralizantes específicos:

Com 56 pares de soro foram feitos testes de neutralização em cultura de tecidos ( TN), para o EV70, usando como antígeno a cepa J6 70/7 (1982), recebida do CDC e cultivada em HEP-2 no IEC, título $1,0 \times 10$ a 5 : potência/ $0,1 \mathrm{ml}$ TCD 50 , e para o vírus isolado, Reg. 31718 , título 1,0

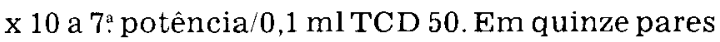
de soro também foi feito o teste de neutralização usando os isolamentos n. 31680 e 31693 , ambos com o título de $1,0 \times 10$ a 7 a potência/ $/ 0,1 \mathrm{ml}$ TCD 50 .

No TN os soros foram diluídos em série com razão igual a 4 . A diluição mínima usada foi 1 $=4$ sendo que a máxima para o soro agudo foi $1=16$ e para o soro convalescente $1=64$. Contra essas diluições foi usada dose única do vírus, igual a 100 TCD 50. Consideramos infecção re cente, quando a diferença de título entre o soro agudo e o soro convalescente foi significativa, isto é, quatro vezes maior.

Paralelamente foram enviados ao CDC, vin te pares de soro para comprovação sorológica.

Quando nảo dispunhamos de soros parea dos dos pacientes nos quais obteve-se isolamento do vírus, ou quando a neutralizaçâo com soro pareado não mostrou-se conclusiva, esses vírus isolados foram neutralizados em culturas celulares pelo soro das amostras identificadas no CDC.

\section{RESULTADOS}

Os dados clínicos dos pacientes deste surto, e que foram registrados no IEC ou relatados por oftalmologistas de Belém, sāo semelhantes àqueles anterioremente observados em outros surtos de CHA.

A doença é contagiosa, de rápida disseminaçāo, a transmissāo se faz de pessoa a pessoa ou através de objetos contaminados com secre ções oculares ou respiratórias, sendo necessário levar em conta ainda a via fecal oral, e o período de incubaçāo é curto, em torno de 3 dias.

Os principais sinais e sintomas observados foram: sensaçāo de corpo estranho, ardência, la- 
SANTOS, E. de O.; MACÉDO, O.; GOMES, M. de L. C. \& NAKAUTH, C. M. - Conjuntivite hemorrágica aguda causada pela variante do coxsackievirus A24, em Belém, Pará, Brasil, 1987. Rev. Inst. Med. trop. S. Paulo, 31(3): 183-187 1989 .

crimejamento, prurido, edema palpebral e hiperemia. A gravidade das manifestaçōes hemorrágicas variou de simples petéquias até manchas hemorrágicas, e foram registradas em $20 \%$ dos pacientes atendidos no IEC, todos eles com mais de 48 horas de doença. Dos nossos atendimentos, $66 \%$ ocorreram dentro das primeiras 48 horas. Outras manifestaçōes relatadas foram: coriza nasal, cefaléia, febre, dor de garganta e adenite pré-auricular.

A distribuição dos pacientes por grupo etário e sexo (Tabela 1), deverá ser interpretada levando-se em conta as características da amostra, $83 \%$ da qual foi colhida entre militares da Aeronáutica, que foram a nós enviados por médicos dessa instituiçāo. Por outro lado a maior concentração de atendimentos ficou na faixa etária de adultos jovens, $20-33$ anos. Não tivemos oportunidade de atender crianças na faixa entre $0-10$ anos.

Os resultados das inoculações feitas em CM e em duas diferentes linhagens celulares, usando 166 espécimes colhidos da conjuntiva e da orofa ringe, estão expostos na tabela 3. Os CM perma neceram sem sinais de doença assim como não foi observado efeito citopático na linhagem celular VERO. Entretanto, doze dias após as primeiras inoculaçōes no laboratório, obtivemos na linhagem HEP-2, o isolamento de um agente com caracteristicas citopáticas dos enterovírus, proveniente de um espécime colhido da conjuntiva.

TABELA 1

Distribuicão por grupo etário e sexo, de 83 casos clínicos de conjuntivite hemorragica aguda causada pela variante do COX A24 - Belém, Pará, Brasil - 1987.

\begin{tabular}{|c|c|c|c|}
\hline \multirow{2}{*}{ Faixa etária } & \multicolumn{2}{|c|}{ Sexo } & \multirow{2}{*}{ Total } \\
\hline & Masculino & Feminino & \\
\hline $0-10$ & - & - & - \\
\hline $11-20$ & $17(20,5 \%)$ & $\ldots$ & $17(20,5 \%)$ \\
\hline $21-30$ & $34(41,0 \%)$ & $2(2,4 \% / n)$ & $36(43,4 \%)$ \\
\hline $31-40$ & $8 \quad(9,6 \%)$ & $3(3,6 \%)$ & $11(13,3 \%)$ \\
\hline $41^{\circ}-50$ & $9(10,8 \%)$ & $1(1,2 \%)$ & $10(12,0 \%)$ \\
\hline$>-\mathbf{5 0}$ & $8(9,6 \%)$ & $1(1,2 \%)$ & $9(10,8 \%)$ \\
\hline Total & $76(91,5 \%)$ & $7(8,4 \%)$ & $83(100 \%)$ \\
\hline
\end{tabular}

OBS: A concentraçāo de casos do sexo masculino se deve a que $83 \%$ da amostra foi colhida entre militares da Aero náutica.
TABELA 2

Resultados dos isolamentos da variante do COX A24 obtidos após a inoculaçāo de 166 espécimes colhidos em 83 pacientes durante o surto de CHA - Belém, Pará, Brasil - 1987

\begin{tabular}{|c|c|c|c|c|c|c|}
\hline \multirow{2}{*}{ Sistemas } & \multicolumn{2}{|c|}{ S. Conjuntiva } & \multicolumn{2}{|c|}{ s. Orofaringe } & \multicolumn{2}{|c|}{ Total } \\
\hline & Pos. & Neg. & Pos. & Neg. & Pos. & $\mathrm{Neg}$ \\
\hline $\mathrm{CM}$ & 0 & 83 & 0 & 83 & 0 & 166 \\
\hline HEP-2 & 51 & 32 & 22 & 61 & 73 & 93 \\
\hline VERO & 0 & 83 & 0 & 83 & 0 & 166 \\
\hline
\end{tabular}

TABELA 3

Resultados dos testes de neutralização (TN) em cultura de tecidos, contra o enterovirus 70 e a variante do COX A24 (VCOX A24), em 56 pares de soro - Belém, Pará, Brasil 1987.

\begin{tabular}{lcr}
\hline Resultado & EV -70 & VCOX A24 \\
\hline $\begin{array}{l}\text { Conversóes sorológicas } \\
\text { Presença de AC. em }\end{array}$ & - & $32(57 \%)$ \\
títulos estacionários & $19(34 \%)$ & $1(2 \%)$ \\
Ausència de anticorpos & $37(66 \%)$ & $23(41 \%)$ \\
\hline
\end{tabular}

Outros isolamentos sucederam-se, 73 ao to do, apenas em HEP -2, quer de "swab" de conjuntiva - cinqüenta e um - quer de "swab" da orofaringe - vinte e dois.

Com a finalidade de identificarmos a cepa obtida, foram feitos testes de neutralização com o "pool" de Melnick e com o soro homólogo do EV70 produzido em coelho e fornecido pelo CDC, sem que se lograsse caracterizar o agente isolado.

Pelo fato de nāo dispormos de soro-imune padrão adequado, enviamos para o CDC com o propósito de identificação correta da cepa, as amostras de registro $31693,31699,31710$ e 31718 . Posteriormente recebemos carta confirmando tratar-se da variante do coxsackievirus A24.

Dos 56 pares de soro com os quais foram feitos testes de neutralização (Tabela 3), obtivemos $32(57 \%)$ conversóes sorológicas para a cepa isolada; 1 par de soro (2\%) apresentou anticorpos para o vírus em títulos estáveis, e $23(41 \%)$ não possuiam anticorpos para o vírus, segundo a metodologia e diluiçāo inicial usada.

Quanto ao EV70, nāo houve conversāo sorológica; $19(34 \%)$ possuiam anticorpos em títulos estáveis compatíveis e sugestivos de infecção an 
SANTOS, E. de O.: MACÉDO, O.: GOMES, M. de L. C. \& NAKAUTH, C. M. - Conjuntivite hemorrágica aguda causada pela variante do coxsackievirus A24, em Belém, Pará, Brasil, 1987. Rev. Inst. Med. trop. S. Paulo, 31(3): 183-187, 1989.

tiga, e $37(66 \%)$ não possuiam anticorpos contra esse agente.

Quer por sorologia, quer por isolamento do vírus, foi possivel fazer o diagnóstico etiológico de certeza da variante do COX A24 em 62 pacien tes, ou seja, em $74,6 \%$ da amostra estudada.

\section{DISCUSSÃO}

O surto de CHA que ocorreu em Belém, 1987, o terceiro notificado nessa cidade no espaço de 6 anos, nāo obstante a diferença entre os agentes, reproduziu nos pacientes quase que exatamente, o mesmo quadro clínico verificado nos surtos anteriores.

As manifestaçōes hemorrágicas que, no caso dos surtos anteriores se instalavam nas primeiras 24 horas, só foram observadas por nós, em pacientes atendidos após 48 horas de doença. O fato de $66 \%$ dos casos terem sido examinados nas primeiras 48 horas, justificaria o percentual relativamente baixo dessas manifestaçōes em nossos registros.

A doença ocorreu indistintamente em am bos os sexos e em todos os níveis sócio-econô micos:

O surto, mais uma vez, coincidiu com os primeiros meses do ano, época em que se verificam os mais altos índices de calor, umidade e pluvio. sidade na região.

A relativa facilidade com que o agente foi isolado, indicou inicialmente tratar-se de um ví rus distinto do EV70, restando a possibilidade de ser a variante do coxsackievirus A24, implicada em extensos surtos da doença na Ásia a partir de 1970 e 1971 e posteriormente de 1975 a $1979^{2}$. 5. 14. 15. Mais recentemente, no final de 1986 e início de 1987, na zona do Caribe, nas ilhas de Trinidad, Jamaica e Santa Cruz ${ }^{6}$, este vírus foi causador de surtos desta infecçāo que, até entāo, no Brasil, só havia sido causada pelo EV70.

A suspeita etiológica foi confirmada pelos resultados do CDC e agora, temos circulando no país os dois vírus mais significativos causa dores de CHA.
Em princípio, a VCOXA24 causa apenas a doença ocular auto-limitada. Pouco sabemos so bre o que vem acontecendo no Brasil no campo das CHA, mesmo com as relacionadas ao EV70, que já está entre nós há 7 anos.

Seria da maior utilidade para a Saúde Públi ca que o laboratório especializado, o oftalmologista - e em se tratando do EV70, também o neurologista - trabalhassem conjuntamente.

O diagnóstico laboratorial das CHA é impor tante, inclusive para possibilitar ao oftalmologista adequar o tratamento às peculiaridades inerentes a cada agente causal.

Vale registrar que a literatura refere a ocorrência de conjuntivite crônica e ulcerações na córnea, associadas ao uso de corticosteróides du rante o tratamento ${ }^{14}$, além do relato de PRAMA $\mathrm{NIK}^{9}$, sugerindo que "mesmo causando um rápido alívio, o tratamento com corticosteróide pode impedir o desenvolvimento de imunidade, permitindo várias recidivas da doença num mesmo paciente".

Com a presença de mais este enterovírus causando CHA no Brasil, será necessário somar esforços para reunir informaçōes que permitam medidas apropriadas de tratamento e controle. durante os surtos.

\section{SUMMARY}

Acute haemorrhagic conjunctivitis caused by coxsackievirus A24 (variant), in Belém, Pará, Brazil, 198\%.

An epidemic of acute haemorrhagic conjunc tivitis in Belém, Pará, Brazil, vas investigated. From 83 patients, 73 samples of virus was isolated in cultures of HEP-2 cells from conjunctival swab and throat swab.

The virus isolates were identified in Centers for Disease Control, Atlanta, Georgia, USA, as an antigenic variant of coxsackievirus A24.

Neutralization Test was done on 56 paired serum samples, using entero virus type 70 (EV70) and virus isolates. 
SANTOS, E. de O.: MACÉDO. O.: GOMES, M. de L. C. \& NAKAUTH. C. M. - Conjuntivite hemorrágica aguda causada pela variante do coxsackievirus A24, em Belem. Pará. Brasil, 1987. Rev. Inst. Med. trop. S. Paulo, 31(3): 183-187, 1989 .

Serological conversions for virus isolates were found in $57 \%$ (32 patients).

\section{AGRADECIMENTOS}

Aos oftalmologistas de Belém que nos deram todo o apoio

À Dra. Corinha Fischer pela atençāo em rever nosso trabalho.

À Da. Léa Costa Lima e sua datilografia perfeita.

À Laura Nakauchi de Souza, Cereja Kazuko Nakauth e Euda Galiza Primo, pelo trabalho cui dadoso.

Ao Sr. Raimundo Paixāo, nosso auxiliar competente.

\section{REFERENCIAS BIBLIOGRAFICAS}

1. ANUARIO Estatistico do Brasil, Rio de Janeiro, IBGE, 1980

2. CHRISTOPHER, S.: THEOGARAJ, S.; GODBOLE, S. \& JOHN, T. J. - An epidemic of acute hemorrhagic conjune tivitis due to coxsackievirus A24. J. infect. Dis., 145: 16.19, 1982

3. GABBAY, Y. B.: FREITAS, R. B.: SANTOS, E. O\& LINHARES, A. C. - Surto de conjuntivite hemorrágica aguda em Belém do Pará (Nota Prévia). Rev. paraen. Med., 3: $93 \cdot 96,1981$

4. LE COINTE, P. - Estado do Pará, a terra, a água e o ar. Belém. Companhia Editora Nacional, 1945, p. 7984.

5. MIRKOVIC. R. R : SCHMIDT, N. J ; YIN MURPHY, M. \& MELNICK, J. L. - Enterovirus etiology of the 1970 Sin gapore epidemic of acute conjunctivitis. Intervirology, 4: 119-127, 1974.
6. MMWR. Acute hemorrhagic conjunctivitis caused by cox sackievirus A24 - Caribbean. MMWR, 36 (16): 245-251. 1987.

7. NÓBREGA, M. J.; DEL REY FILHO. M. \& BELFORT JR., R. - Estudo prospectivo de casos de conjuntivite viral aguda na cidade de $S$. Paulo. Caracterizaça do ente rovirus 70 (conjuntivite hemorragica aguda). Rev. Ass. méd. bras., $32: 4750,1986$

8. OPAS - OMS. Epidemia de conjuntivitis hemorrágica aguda. Bol. epidem. OPS, 2 (5): 7, 1981

9. PRAMANIK. D. D. - An epidemic of conjunctivitis in India. Practitioner, 207: 805 806. 1971

10. SANTOS, E. O.; GABBAY, Y. B ; FREITAS, R. B \& LI NHARES, A C. - Surto de conjuntivite hemorrágica agu da no Norte do Brasil. Bol. epidem. (Rio de J.), 15 (2): $1.11,1983$.

11. SANTOS, E. O.: MACEDO, O.: GOMES, M. L. C. \& NA KAUTH, C. M. - Conjuntivite hemorrágica aguda em Cuiabá, Mato Grosso, Brasil, 1983. Rev. Inst. Med. trop. S. Paulo, 29: 4752,1987

12. SANTOS, E. O.: MACEDO, O. \& NAKAUTH. C. M. Conjuntivite hemorrágica aguda por EV70. In: Instituto Evandro Chagas: 50 anos de contrihuição às cièncias biológicas e à medicina tropical. Belém, Fundação Serviços de Saúde Pública, 1986. v. 2, p. 717-730

13. TAYLOR, J, W.: CHANDLER, J, W. \& COONEY, M. K - Acute hemorrhagic conjunctivitis associated with ade novirus type 19. New Engl. J. Med., 292: 978 979, 1975.

14. YIN MURPHY, M. - Acute hemorrhagic conjunctivitis Prog. med. Virol, 29: 23-44, 1984

15. YIN MURPHY, M. - An epidemic of picornavirus con junctivitis in Sigapore. Southeast Asian J. trop. Med. publ. Hlth., 3: 303-309, 1972

Recebido para publicacáo em 28/12/1988. 